The University of Maine

\title{
DigitalCommons@UMaine
}

Earth Science Faculty Scholarship

Earth Sciences

1980

\section{Himalayan and Trans-Himalayan Glacier Fluctuations and the South Asian Monsoon Record}

Paul Andrew Mayewski

University of Maine, paul.mayewski@maine.edu

Gerard P. Pregent

Peter A. Jeschke

Naseeruddin Ahmad

Follow this and additional works at: https://digitalcommons.library.umaine.edu/ers_facpub

Part of the Glaciology Commons, and the Hydrology Commons

\section{Repository Citation}

Mayewski, Paul Andrew; Pregent, Gerard P.; Jeschke, Peter A.; and Ahmad, Naseeruddin, "Himalayan and Trans-Himalayan Glacier Fluctuations and the South Asian Monsoon Record" (1980). Earth Science Faculty Scholarship. 184.

https://digitalcommons.library.umaine.edu/ers_facpub/184 


\title{
HIMALAYAN AND TRANS-HIMALAYAN GLACIER FLUCTUATIONS AND THE SOUTH ASIAN MONSOON RECORD
}

\author{
Paul A. Mayewski,${ }^{*}$ Gerard P. Pregent,$\dagger$ Peter A. Jeschke, ${ }^{*}$ and Naseeruddin Ahmad $\ddagger$
}

\begin{abstract}
Termini fluctuations for glaciers in the Himalayas and Trans-Himalayas are examined for the period AD 1850 to 1960 . This period can be characterized as one of general retreat. Differentiation by geographic subdivision, however, reveals that Himalayan glaciers (best exemplified in Lahaul-Spiti, Kolahoi, Nanga Parbat, and Garwhal) show consistent retreat throughout the period, while Trans-Himalayan glaciers (best exemplified on the north side of the Karakoram and in Batura Mustagh and Rakaposhi-Haramosh) deviate from this pattern by displaying a major period of advance from AD 1890 to 1910.

Although no apparent relationship exists between the magnitude of termini advances

and glacier lengths, termini retreat records are commonly characterized by short- to mediumlength glaciers $(<30 \mathrm{~km})$. Termini advances are, however, related to flow direction; advancing termini most commonly face east, southeast, northwest, and west. Glaciers characterized predominantly by retreat flow commonly, but not exclusively, east and southeast.

Advances of Trans-Himalayan glaciers during the period AD 1890 to 1910 are attributed to strengthened monsoon wind currents and to secular variations in Indian rainfall. Such changes in the general atmospheric circulation, implied by climatic data, produce subsequent increases of moisture influx to the Asian land mass.
\end{abstract}

\section{INTRODUCTION}

Advances in climate prediction depend on knowledge of historical climatic sequences ranging in scale from decades to millennia. Proxy data provided by pollen, sediments, tree rings, glaciers, etc., are used to construct these sequences when direct observations of the atmosphere are either spatially or temporally lacking. Links between the proxy data and the atmosphere generate the most confi-

\footnotetext{
*Department of Earth Sciences, University of New Hampshire, Durham, New Hampshire 03824.

$\dagger$ New Hampshire State Climatologist, University of New Hampshire, Durham, New Hampshire 03824.

§Department of Geology, Aligarh Muslim University, Aligarh, India 202001.

0004-0851/80/020171-12\$01.80

(C) 1980 , Regents of the University of Colorado
}

dence when there is an understanding of the physical relationship between the two.

The purpose of this paper is to examine and promote interest in possible links between glacial activity in the Himalayas and TransHimalayas and fluctuations in the southwest monsoon of India. The physical relationship between the monsoon and glaciers may be associated with flux of moisture and heat. Studies conducted in the Nepalese portion of the Himalayas (Fugii et al., 1976; Ageta and Satow, 1978; Ikegami and Inone, 1978) support this contention. The period of record is AD 1850 to 1960 .

The quality of available data sets and the uncertainties regarding response times of glaciers force a number of compromises relating to statistical procedures. First, advances and

P. A. Mayewshi et al. / 171 
retreats are defined only on the basis of snout positions; historical records do not allow a more refined approach. Second, it is assumed that monsoon disturbances, rather than extratropical disturbances, dominate the precipitation affecting the glaciers; the interaction between mid-latitude systems and the southwest monsoon deserves more attention than is pos- sible in this paper, but the importance is acknowledged (Rao, 1976). Third, a somewhat questionably homogeneous data set is compiled by merging small and discontinuous samples; although such treatment may conflict with statistical principles, definitive results are not possible regardless of the handling of the data.

\section{THE SAMPLE POPULATION}

Mayewski and Jeschke (1979) have summarized 112 fluctuation records, spanning the period AD 1850 to 1969 , of glaciers in the Himalayas (Everest-Kanchenjunga, Garwhal, Lahaul-Spiti, Kolahoi, and Nanga Parbat) and in the Trans-Himalayas (north and south sides of the Karakoram, Rakaposhi-Haramosh, Batura Mustagh, and Khunjerab-Ghujerab). The data set analyzed in this paper is drawn from these glacier fluctuation records. The geographic distribution of the glaciers in the data set appears, by $10-y r$ periods, in Figure 1. It spans an area approximately $1800 \times 270 \mathrm{~km}$ measured northwest to south- east and northeast to southwest, respectively, and covers parts of India, Pakistan, China, Nepal, and Bhutan.

The geographic distribution of the sample population is listed in Table 1. As is evident from Table 1 and Figure 1, the sample population is composed primarily of glaciers located to the west of Everest-Kanchenjunga. Subsequent discussion in this paper deals primarily with these western glaciers. Of this western grouping, northern glaciers, from both sides of the Karakoram, are best represented.

The range in length for the composite

TABLE 1

Number of glacier observations by geographic location

\begin{tabular}{lcrlc}
\hline \hline \multicolumn{1}{c}{ Himalayas } & & & \multicolumn{2}{c}{ Trans-Himalayas } \\
\cline { 1 - 2 } \cline { 5 - 5 } \multicolumn{1}{c}{ Area } & Number & & Area & Number \\
\hline Everest-Kanchenjunga & 5 & & Karakoram (south side) & 28 \\
Garwhal & 18 & & Rakaposhi-Haramosh & 9 \\
Lahaul-Spiti & 3 & & Batura Mustagh & 10 \\
Kolahoi & 2 & & Karakoram (north side) & 27 \\
Nanga Parbat & 6 & & Khunjerab-Ghujerab & 4 \\
\hline
\end{tabular}

TABLE 2

Percent frequency distribution of glacier length $(\mathrm{km})$ for the sample population

\begin{tabular}{cc}
\hline \hline Percent & Glacier length $(\mathrm{km})$ \\
\hline 40 & $0-10$ \\
31 & $10-20$ \\
18 & $20-30$ \\
4 & $30-40$ \\
2 & $40-50$ \\
3 & $50-60$ \\
1 & $60-70$ \\
1 & $70-80$ \\
\hline
\end{tabular}

TABLE 3

Percent frequency distribution of glacier flow directions, to the nearest $45^{\circ}$, for the composite sample population

\begin{tabular}{cl}
\hline \hline Percent & Glacier Flow Direction \\
\hline 20 & North \\
10 & Northeast \\
17 & East \\
11 & Southeast \\
14 & South \\
4 & Southwest \\
12 & West \\
12 & Northwest \\
\hline
\end{tabular}


sample population is 3 to $75 \mathrm{~km}$. The percent frequency distribution of lengths appears in Table 2. From Table 2 it becomes apparent that the sample population deals primarily with glaciers less than $30 \mathrm{~km}$ long.

The percent frequency distribution of flow directions (all glaciers), regardless of geographic location, appears in Table 3. The sample population included a fairly uniform assemblage of flow directions exclusive of the southwest.

\section{SYNTHESES OF FLUCTUATION RECORDS}

The 112 fluctuation records summarized by Mayewski and Jeschke (1979) and used in this study are divided into three types: advance, stillstand, and retreat as defined by the movement of glacier termini. Although we would have preferred to have used additional data concerning changes in glacier dimensions to define glacier regimes, the glaciological literature available from the Himalayas and TransHimalayas rarely includes such details. Final analyses of the relationship between glacier termini changes and regime will depend upon future field investigations. With the currently available data, the sample population can be analyzed by (1) forming a composite of glaciers, (2) regional geographic location, (3) local geographic location, (4) glacier length, and (5) glacier flow direction.

\section{Composite}

For the study period AD 1850 to 1960 the composite sample (Figure 2) is primarily characterized by termini in retreat. The only major departure from this sequence occurs during the period $\mathrm{AD} 1890$ to 1910 when records of advancing termini form the primary regime.

\section{Regional Geographic Location}

For purposes of refining the composite record, the sample population is divided into two broad geographic groupings: Himalayan and Trans-Himalayan (Figure 2). Himalayan glaciers make up the southwestern grouping and Trans-Himalayan glaciers the northeastern grouping (Figure 1). The dividing line runs northwest-southeast between these ranges. This analysis is similar to that conducted by Mayewski and Jeschke (1979), except that the data used here excluded the interpolated data from their study. In general, Himalayan glaciers have been retreating throughout the period AD 1850 to 1960 . Similarly, advance records play a secondary role appearing only during the period AD 1850 to 1910.
Trans-Himalayan glaciers display a more complicated fluctuation record. Retreat forms the primary component of this record during $\mathrm{AD} 1850$ to $1860, \mathrm{AD} 1880$ to 1890 , and AD 1910 to 1960 . Stillstand records are available for the period AD 1890 to 1940 . The most dramatic perturbation in the record comes during the period AD 1890 to 1910 when advances dominate. This major period of advance is followed by a gradual decline in the number of advancing termini. During this period of decline, the number of stillstand records increases moderately and is suggestive of the beginning of a transition back to a retreat regime. The peak in number of advance records noted during the period AD 1860 to 1870 is based upon only a limited number of observations. In fact, this period may be better characterized as transitional between advance and retreat as is the period AD 1870 to 1880 .

\section{Logal Geographic Logation}

In stylized form, Figure 1 displays the type of glacier fluctuation record and magnitude of termini movement available from the data set. Areas containing glaciers with records of advance include north and south sides of the Karakoram, Rakaposhi-Haramosh, Batura Mustagh, Khunjerab-Ghujerab, Nanga Parbat, and Lahaul-Spiti. Advances are the dominant state of activity during the period AD 1890 to 1910 in areas such as the north side of the Karakoram (Mason, 1930; Mercer, 1975), Batura Mustagh, and Rakaposhi-Haramosh. Although advances, in general, do not dominate the periods prior to 1890 and following 1910 , they do occur during the period AD 1850 to 1860 (north side of the Karakoram and to lesser degrees in areas such as south side of the Karakoram, Batura Mustagh, and Rakaposhi-Haramosh), during the period AD 1910 to 1940 (Khunjerab-Ghujerab, north side of the Karakoram, and Batura Mustagh), and during the period AD 1940 to 1960 (north side of the Karakoram). 
Stillstands appear most obviously in the record during the period AD 1900 to 1940 for the north and south sides of the Karakoram, and to a lesser degree for areas such as Nanga Parbat and Garwhal. All of the areas depicted in Figure 1 contain glaciers that show evidence of retreat at some time between the dates $\mathrm{AD}$ 1850 and 1960 . The areas displaying the most continuous records of retreat are in the Hima- layas and include Garwhal, Lahaul-Spiti, Kolahoi, and Nanga Parbat.

\section{Glacier Length}

A comparison of glacier length with the magnitude and timing of termini movements is shown in Figure 3. Conclusions to be drawn from Figure 3, although biased by the overwhelming majority of glaciers less than $30 \mathrm{~km}$
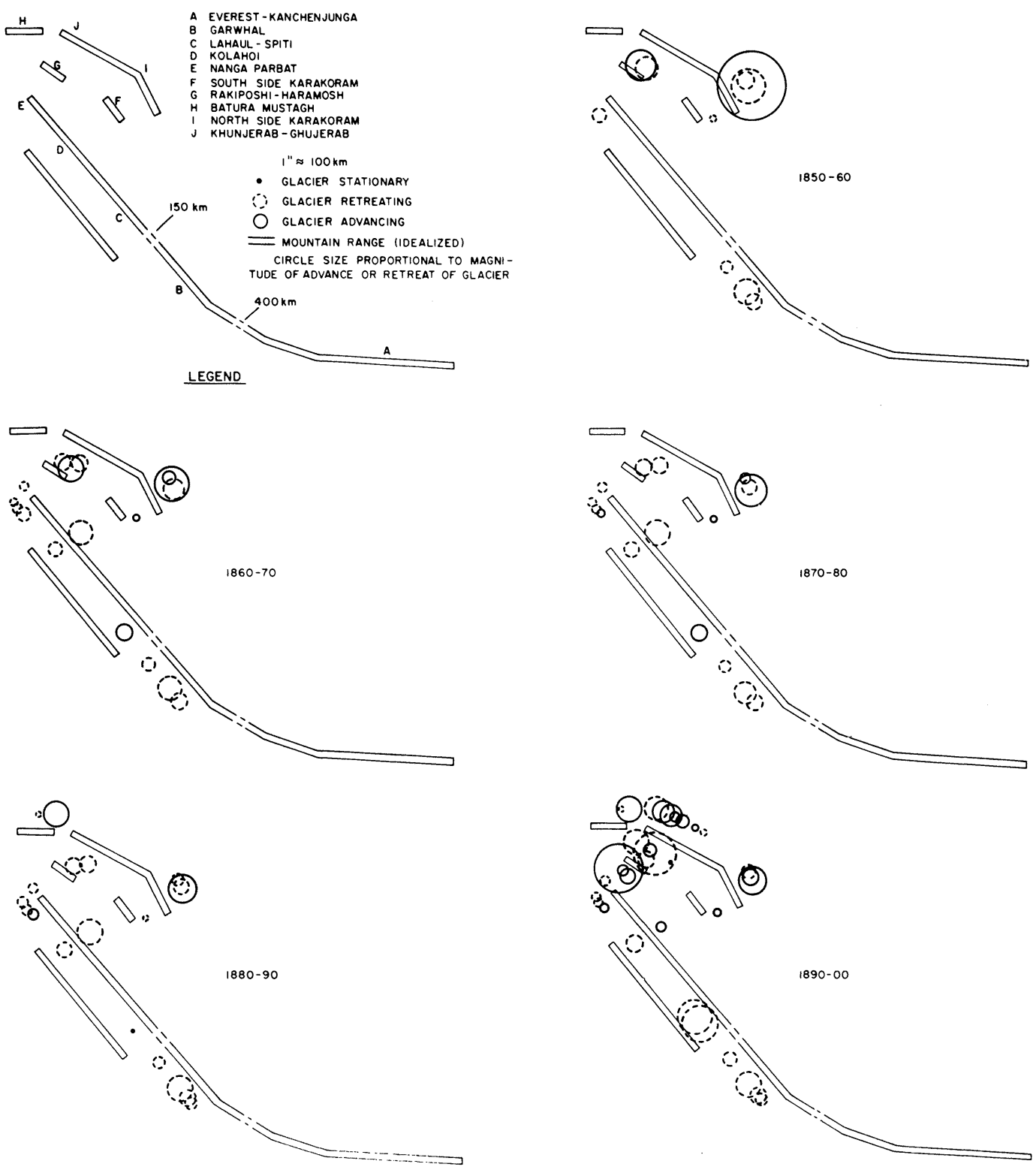

Figure 1. Decadal representation of glacier termini fluctuations (type and relative magnitude). 
in length, involve relationships among glacier length, rate of termini retreat, and the timing of advances and retreats.

In general, short to medium length glaciers $(<30 \mathrm{~km})$ display changes in the position of their termini in the range of 1 to $40 \mathrm{~m} \mathrm{yr}^{-1}$. Long glaciers $(>30 \mathrm{~km}$ ) display smaller magnitude changes in termini position on the order of less than $10 \mathrm{~m} \mathrm{yr}^{-1}$. Several glaciers
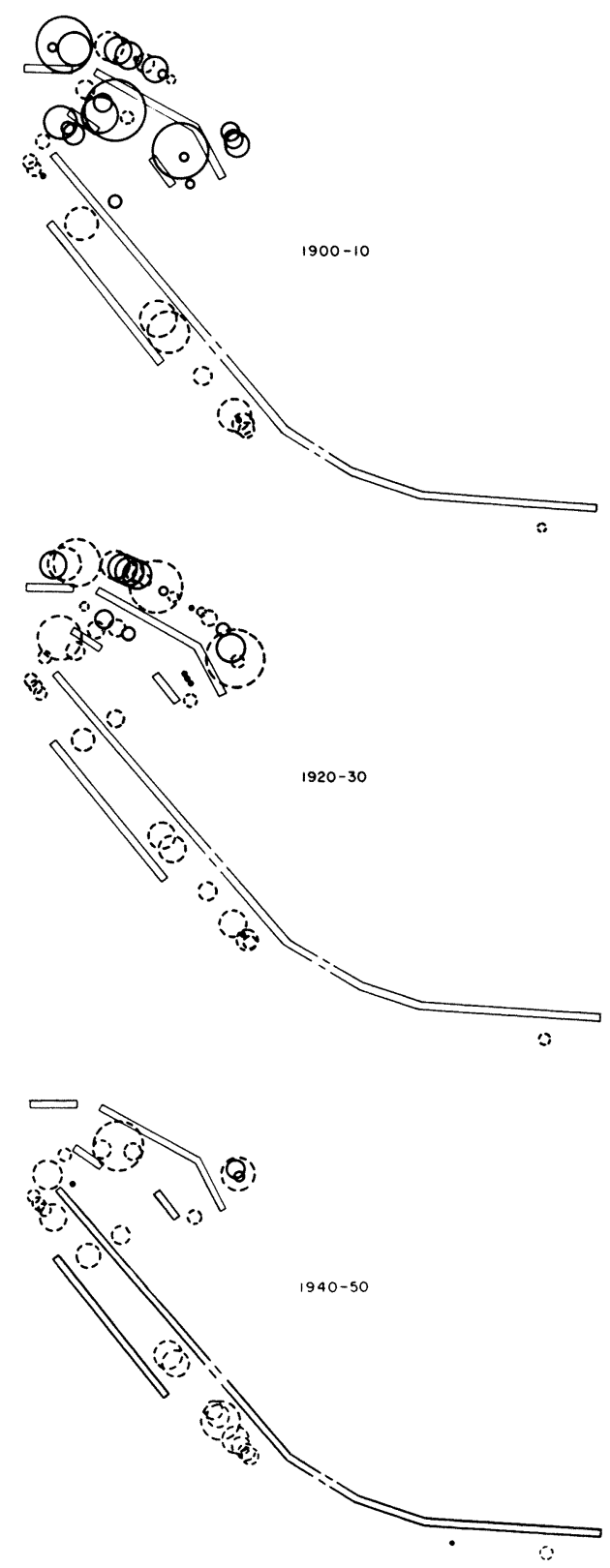

display anomalously high rates of advance or retreat including Aktash (AD 1850 to 1860), Minapin (AD 1890 to 1900), Biafo and Pasu (AD 1900 to 1910), and Kichik Kumdan (AD 1930 to 1940). As summarized by Mayewski and Jeschke (1979), the anomalous character of these glaciers is believed to be due to surging.

While short to medium length glaciers ap-
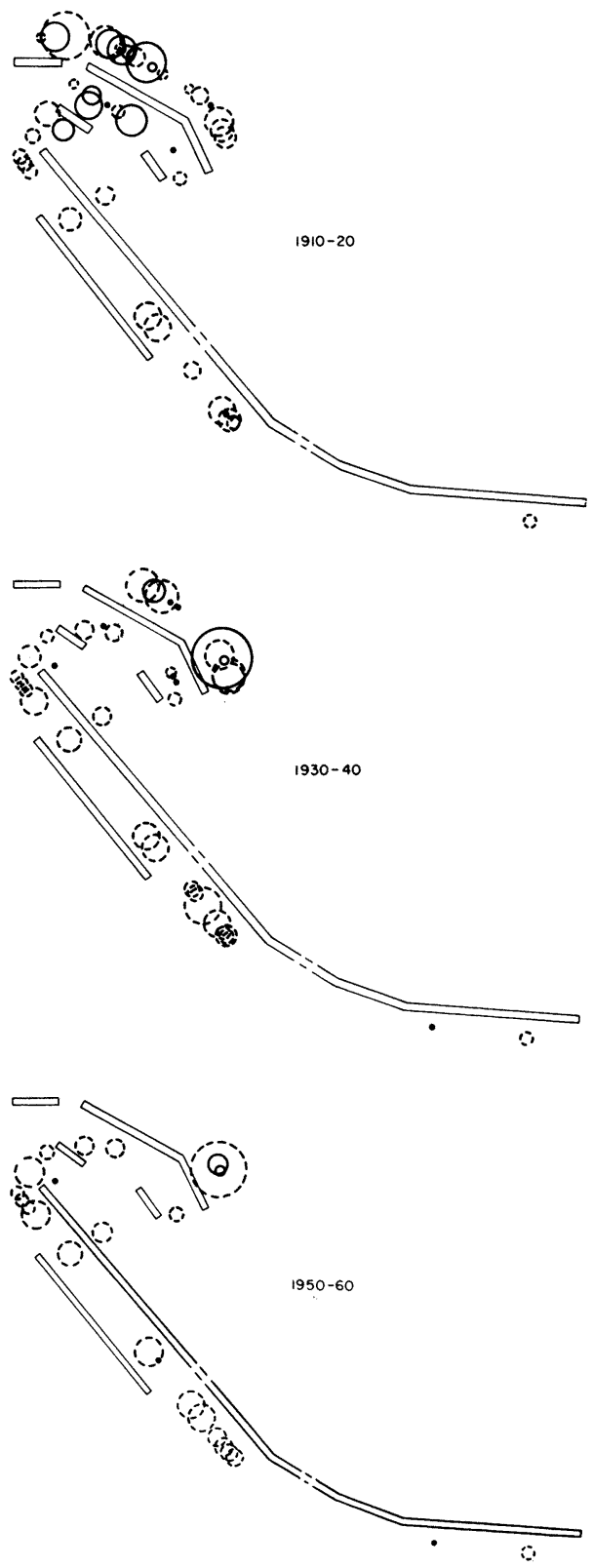

Figure 1. (cont.) 

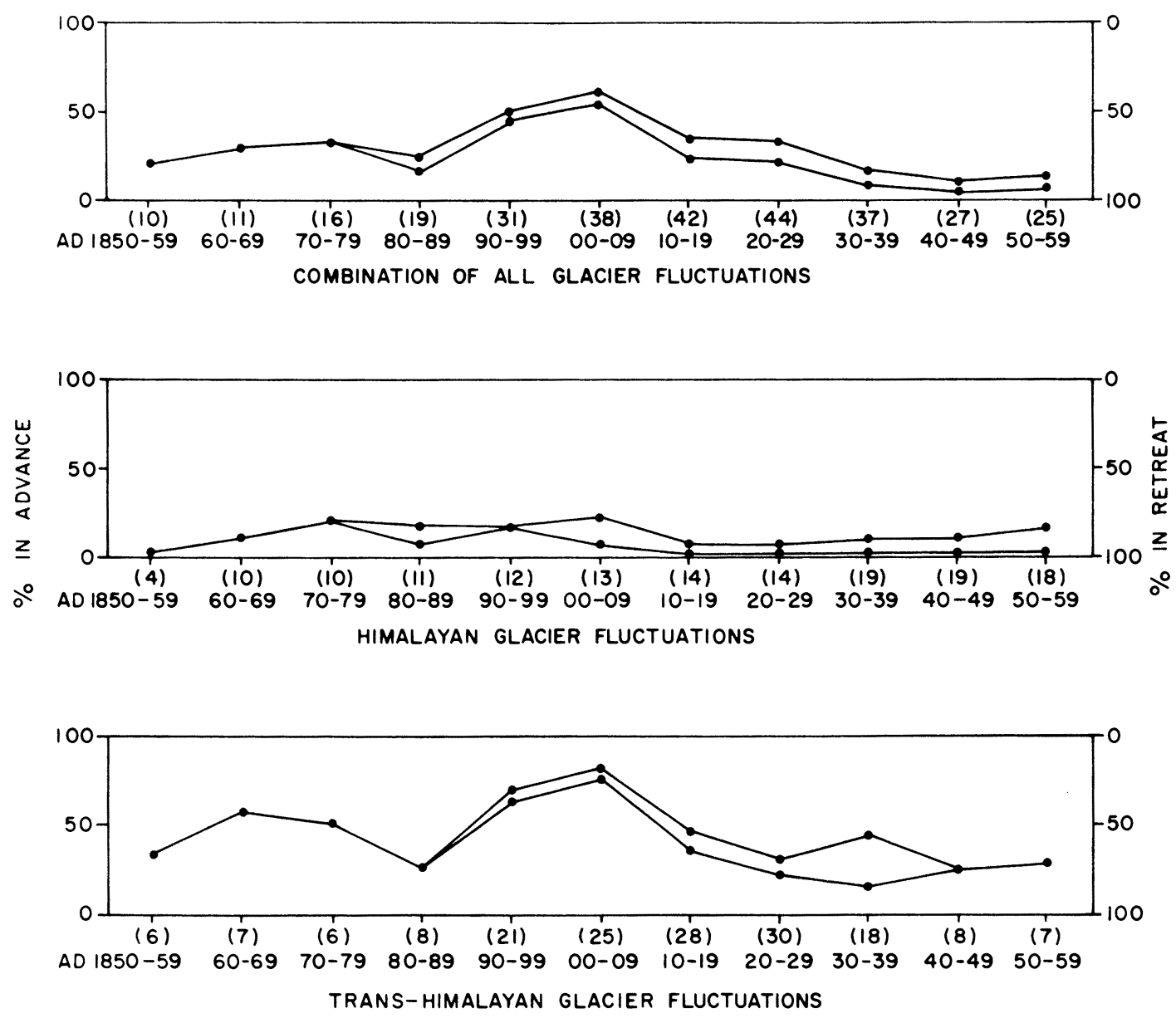

FiguRE 2. Decadal percentages of retreating, stationary and advancing glaciers for composite, Himalayan and Trans-Himalayan samples. Numbers of observations appear in parentheses. Top lines-advances, bottom lines - retreats. Percentage of stationary glaciers represented by separation of lines.

TABLE 4

Flow direction, to the nearest $45^{\circ}$, versus timing of advance and retreat for the composite sample population

\begin{tabular}{lll}
\hline \hline & \multicolumn{1}{c}{ Flow Direction } \\
\cline { 2 - 3 } 10 -yr period & \multicolumn{1}{c}{ Advance } & \multicolumn{1}{c}{ Retreat } \\
\hline $1850-1960$ & $\mathrm{SE}>\mathrm{E}$ & $\mathrm{E}>[\mathrm{SE}=\mathrm{SW}]>[\mathrm{NW}=\mathrm{NE}]$ \\
$1860-1870$ & $\mathrm{E}>[\mathrm{N}=\mathrm{SE}]$ & $\mathrm{SE}>[\mathrm{E}=\mathrm{SW}]>[\mathrm{NW}=\mathrm{N}]$ \\
$1870-1880$ & {$[\mathrm{E}=\mathrm{SE}]>\mathrm{N}$} & $\mathrm{SE}>[\mathrm{NW}=\mathrm{SW}=\mathrm{E}]>\mathrm{N}$ \\
$1880-1890$ & $\mathrm{SE}>\mathrm{E}$ & $\mathrm{SE}>\mathrm{E}>[\mathrm{NW}=\mathrm{SW}=\mathrm{W}]$ \\
$1890-1900$ & $\mathrm{~N}>\mathrm{E}>\mathrm{SE}>\mathrm{S}$ & $\mathrm{SE}>\mathrm{E}>[\mathrm{N}=\mathrm{NE}=\mathrm{SW}=\mathrm{W}=\mathrm{NW}]$ \\
$1900-1910$ & $\mathrm{E}>\mathrm{N}>[\mathrm{SE}=\mathrm{E}]>\mathrm{NE}=\mathrm{NW}$ & $\mathrm{SE}>\mathrm{N}>[\mathrm{SW}=\mathrm{NW}]>\mathrm{W}>\mathrm{E}$ \\
$1910-1920$ & $\mathrm{~N}>\mathrm{E}>[\mathrm{NE}=\mathrm{SW}=\mathrm{NW}]$ & {$[\mathrm{E}=\mathrm{SE}=\mathrm{NW}]>[\mathrm{SW}=\mathrm{N}]>\mathrm{W}>[\mathrm{S}=\mathrm{NE}]$} \\
$1920-1930$ & $\mathrm{~N}>[\mathrm{NE}=\mathrm{E}]>\mathrm{W}$ & $\mathrm{N}>\mathrm{SE}>\mathrm{E}>\mathrm{NW}>\mathrm{SW}>[\mathrm{W}=\mathrm{S}]$ \\
$1930-1940$ & $\mathrm{E}>\mathrm{NW}$ & $\mathrm{SE}>[\mathrm{E}=\mathrm{N}]>\mathrm{NW}>[\mathrm{SW}=\mathrm{S}=\mathrm{NE}]>\mathrm{W}$ \\
$1940-1950$ & $\mathrm{E}$ & $\mathrm{SE}>\mathrm{E}>\mathrm{N}>\mathrm{SW}>[\mathrm{NW}=\mathrm{NE}]>[\mathrm{S}=\mathrm{W}]$ \\
$1950-1960$ & $\mathrm{E}$ & $\mathrm{SE}>\mathrm{E}>[\mathrm{N}=\mathrm{NW}]>\mathrm{SW}>\mathrm{W}$ \\
\hline
\end{tabular}

176 / Arctic and Alpine Research 
pear to dominate the retreat record, the advance record is comprised of variable length glaciers with the majority in the length range short to medium. Longer glaciers dominate the advance record during the periods $\mathrm{AD}$ 1850 to 1860 and AD 1950 to 1960 . In both cases, these periods are at the end of, or close to the end of regional periods of advance. No specific length glaciers dominate the advance record of AD 1900 to 1930 nor the retreat records of AD 1860 to 1870 and $\mathrm{AD} 1890$ to 1900. The remainder of the retreat and advance records is dominated by the short to medium length glaciers.

\section{Glacier Flow Direction}

A plot of glacier flow direction, against magnitude and type of termini fluctuation, appears in Figure 3. Table 4 summarizes the relationship between flow direction and type of terminus fluctuation. The order given for each entry under the Advance and Retreat columns in Table 4 reflects the relative dominance of flow directions in the record. This table does reflect the population frequency distribution of flow directions (Table 3 ) and hence, contains biases against the southwest direction which has a low frequency.

Advancing glaciers, regardless of time period, flow most commonly toward the east, southeast, northwest, and north. Southerly and westerly flowing glaciers rarely display advance records. Retreat records are displayed by glaciers flowing in all directions with southeasterly and easterly flowing glaciers showing a slight maximum.

\section{ATMOSPHERIC CIRCULATION}

The monsoon flow associated with the Himalayas and Trans-Himalayas is depicted in Figure 4. Distinct wet and dry seasons result from systematic changes in air-mass trajectory and in the large-scale pattern of divergence. These changes are controlled by the thermally induced pressure differences between land and ocean and are tied closely to the dynamics of the upper air flow, including the jet stream (Ramage, 1971). The position of the jet stream is in turn related to the zonality and meridianality of flow of adjacent regions, e.g., the North Pacific, the Mediterranean, and Australia. Influx of moisture and heat to the Asian land mass is affected by meridianal flow (Lamb, 1972). A logical extension of these premises is to assume that glaciers in the Himalayas and Trans-Himalayas are influenced by changes in the influx of moisture and heat and by interannual variations in the character of the monsoon.

Historical variations in the character of the monsoon are documented by Lamb and Johnson (1966), and by Parthasarathy and Mooley (1978). Lamb and Johnson describe secular variations in circulation indices of the southwest monsoon, while Parthasarathy and
Mooley describe secular variations in Indian rainfall generated by the southwest monsoon.

Figure 5 provides a comparison between one of Lamb and Johnson's (1966) circulation indices, Parthasarathy and Mooley's (1978) series of Indian rainfall, and Trans-Himalayan glacier fluctuations. The circulation index consists of the sea-level pressure difference between $10^{\circ} \mathrm{N}$ and $20^{\circ} \mathrm{E}$; this index is a direct reflection of the strength of the southwest monsoon flow. The Indian rainfall represents area-weighted averages based on a large number of gauges. Few of these gauges were located in the Trans-Himalayas; it is difficult to circumvent this shortcoming because of the paucity of observations in mountainous terrain.

The monsoon flow begins to strengthen within the period AD 1880 to 1889 and peaks within the period AD 1890 to 1920 . The rainfall series has noticeable minima for the periods $\mathrm{AD} 1850$ to 1859 and AD 1900 to 1909. The glacier fluctuations show peaks for the periods $\mathrm{AD} 1860$ to 1869 , AD 1900 to 1909, and AD 1930 to 1939 with the peak for AD 1900 to 1909 being the most prominent.

\section{DISCUSSION}

Around the turn of the 20th century, TransHimalayan glacier termini showed advances analogous to glaciers in other parts of the world such as the Swiss Alps (Kasser, 1967; Hoinkes, 1968), north Greenland (Weidick, 1972), and Swedish Lapland (Karlén, 1973). 

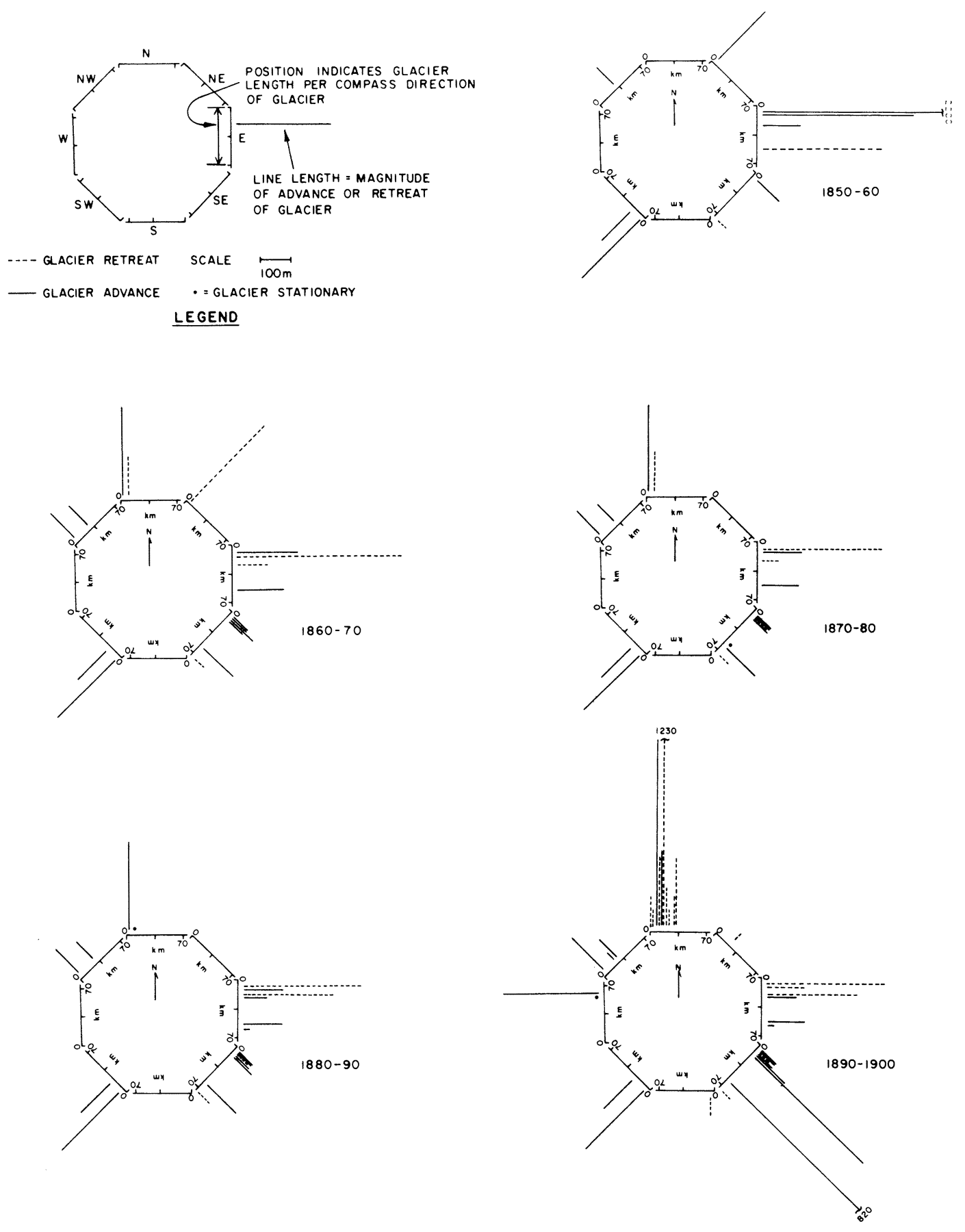

FIGURE 3. Decadal representation of glacier flow direction, glacier length, and termini movement.

178 / Arctic and Alpine Research 

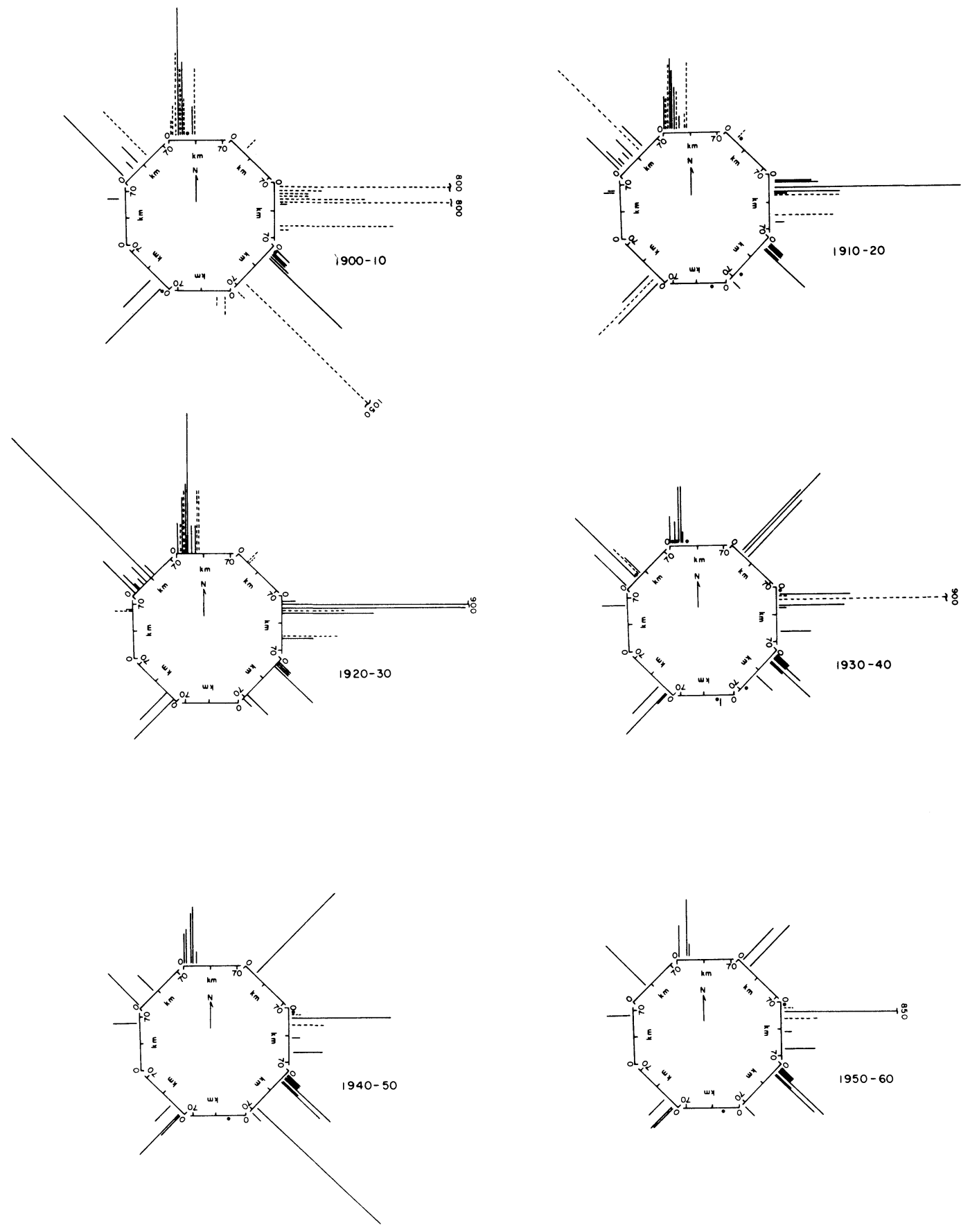

Figure 3 (cont.)

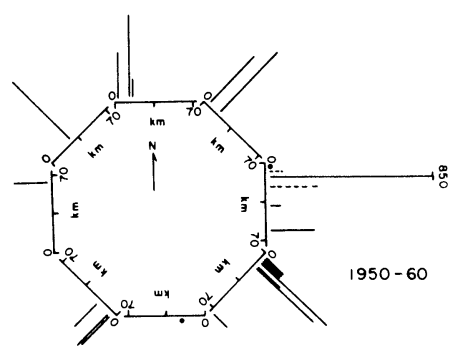

P. A. Mayewski et al. / 179 
Himalayan glaciers did not show advances during this same time period perhaps because, by comparison with Trans-Himalayan glaciers they have lower elevations and associated higher ablation rates in the Trans-Himalayas.

With respect to the period AD 1900 to 1909 , Figure 5 indicates that when a high percentage of the Trans-Himalayan glaciers were advancing (when snout positions were advancing), monsoon rainfall was somewhat diminished; at the same time, the monsoon flow was evidently enhanced. The coincidence of diminished rainfall and enhanced flow seems incongruent and requires a closer look at the synoptic climatology during this period. Perhaps this diminished rainfall was not representative of the Himalayas and TransHimalayas; such a possibility is supported by DeTerra and Hutchinson (1934) who present evidence of high lake levels in the Tibetan highlands around the turn of the century.

Another important consideration is glacier response time. The response time of a glacier can be approximated by Paterson's (1969: 208) relation:

$$
R=\frac{1}{4\left(\partial \epsilon_{x} / \partial t\right)}
$$

where $R$ is response time in years, $\epsilon_{x}$ is the longitudinal strain rate at the surface, $t$ is time, and $\partial \epsilon_{x} / \partial t$ is in $y^{-1}$; as noted by Paterson (1969: 208) the strain rate for valley glaciers is commonly on the order of $10^{-1}$ to $10^{-2} y^{-1}$ yielding response times on the order of 2.5 to $25 \mathrm{yr}$. Absolute values of Trans-Himalayan and Himalayan glacier response times are not known, but the physical characteristics of these glaciers would suggest that their response times are similar to those of other valley glaciers.

If we suppose that the natural range of response times of temperate glaciers is 2.5 to $25 \mathrm{yr}$, two possibilities can be cited; for fast response times, the Trans-Himalayan glacier advances during the period AD 1900 to 1909 may reflect increased mountain precipitation during approximately the same period. This first possibility infers that the diminished monsoon rainfall of principally the lowland stations was not reflected in the northern mountainous regions. For long response times, the advances during AD 1900 to 1909 may have resulted from the earlier maxima in the monsoon rainfall series centered around AD 1880 to 1889.

Inferences play a significant role in the development of this paper. This usually becomes a necessity when data are insufficient to support a quantitative description of the physical

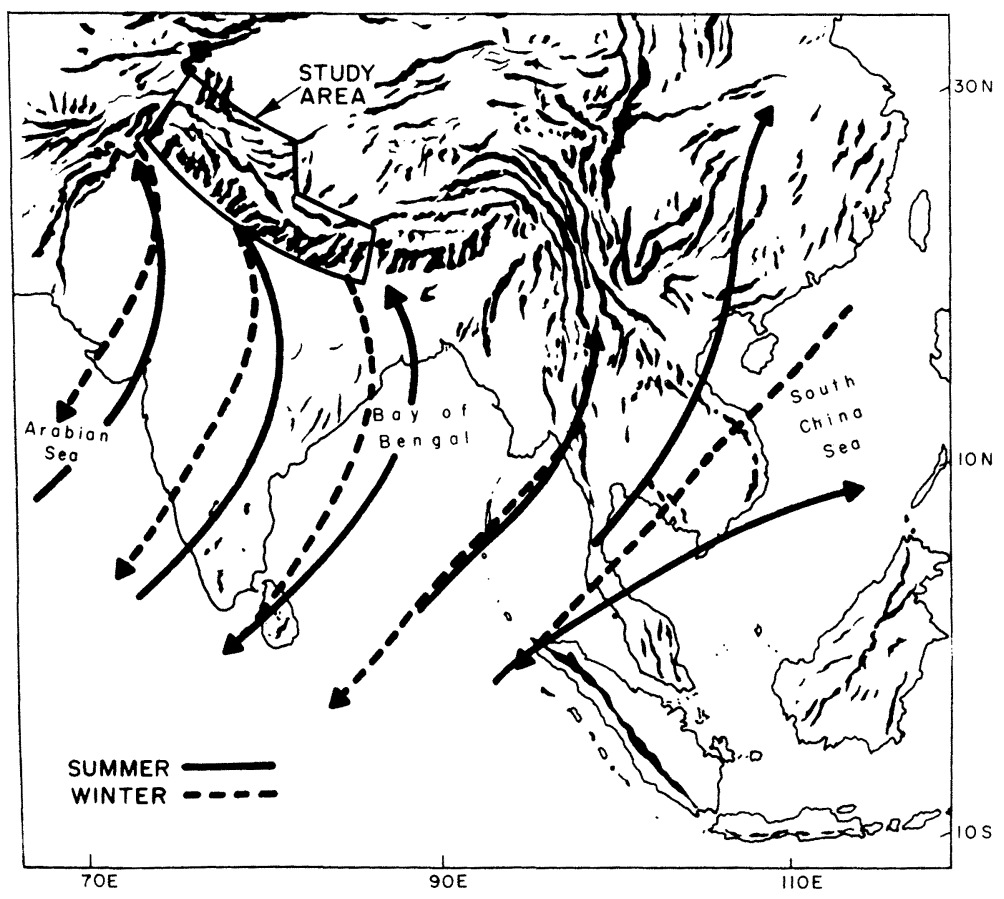

Figure 4. Surface air movement for Asian monsoon. Summer monsoon (solid line); winter monsoon (dashed line).

180 / Arctic and Alpine Research 

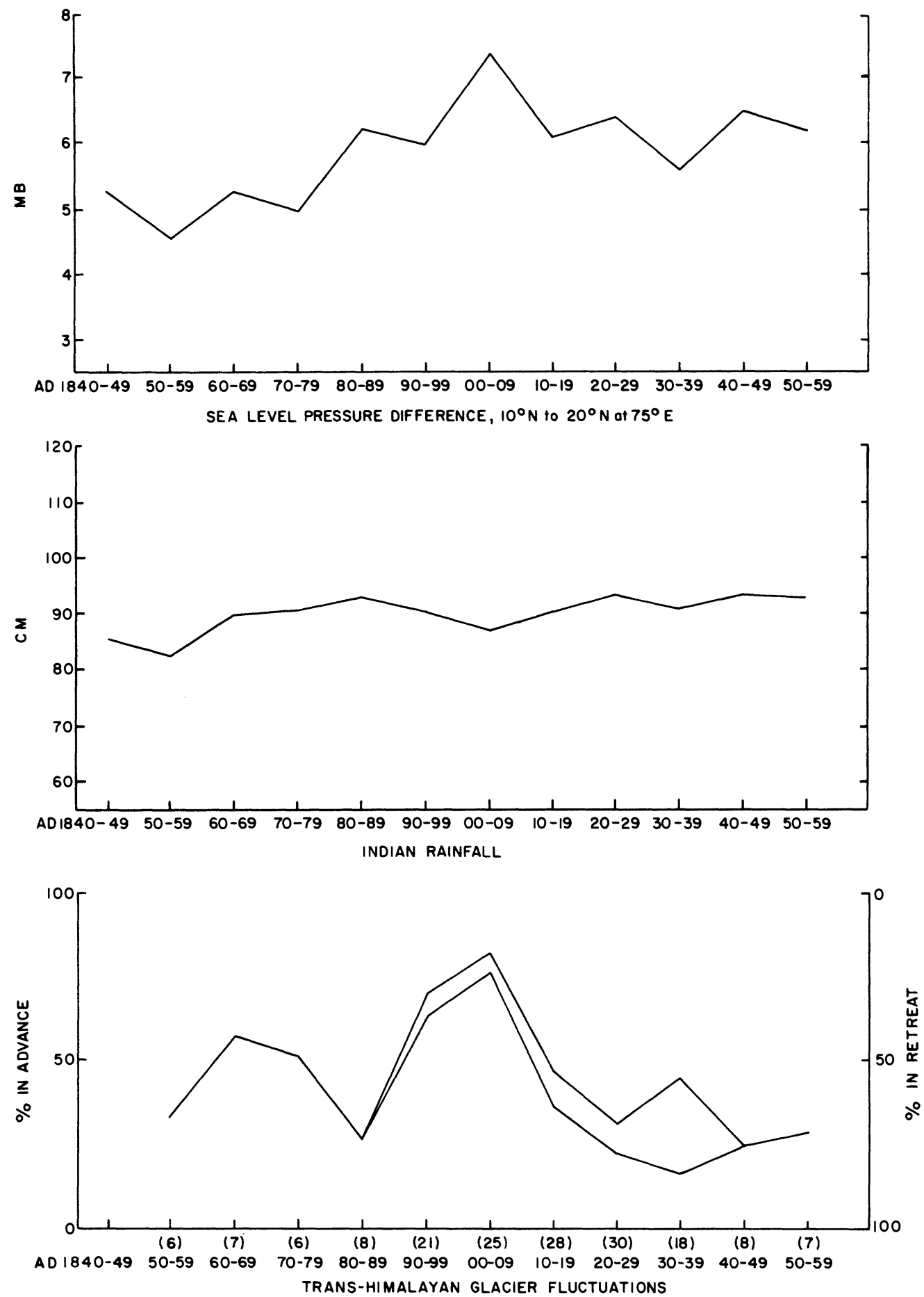

FIGURE 5. Upper: Strength of monsoon current at $75^{\circ} \mathrm{E}$ (based on difference of surface air pressure [mb] between 10 and $20^{\circ} \mathrm{N}$; data from Lamb and Johnson, 1966: 94). Middle: Area-weighted Indian rainfall (data from Parthasarathy and Mooley, 1978: 773). Lower: Decadal percentages of retreating, stationary and advancing Trans-Himalayan glaciers. 
link between atmospheric and glaciological processes operating on either a local or a hemispherical scale. The inference that Trans-Himalayan glacier termini movement is related to circulation indices of the Indian Ocean sector and, through teleconnections, to circulation indices of other regions of the globe is attempted because a sizable population of glaciers is used. Individual glaciers often respond in unique ways to external stimuli. However, when numerous glaciers in a region, each subject to its own local environment, respond in a consistent manner, it becomes apparent that some particular external stimulus dominates the local environments;

\section{ACKNOWLEDGMENTS}

We wish to thank Warren Celli (College of Engineering and Physical Sciences) for drafting the figures used in this text and the Central University Research Fund of the University of New Hampshire for providing the financial support required to undertake this program.

\section{REFERENCES CITED}

Ageta, Y. and Satow, K., 1978: Study of the mass balance of small glaciers in Khumbu Himal during the summer monsoon season. Seppyo (Journal of the Japanese Society of Snow and Ice), 40: 4-11.

DeTerra, H. and Hutchinson, G. E., 1934: Evidence of recent climatic changes shown by Tibetan highland lakes. Geographical Journal, 84(4): 311-320.

Fujii, Y., Nakawo, M., and Shrestha, M. L., 1976: Mass balance studies of glaciers in Hidden Valley, Mukut Himal. Seppyo (Journal of the Japanese Society of Snow and Ice), 38: 17-21.

Hoinkes, C. H., 1968: Glacier variations and weather. Journal of Glaciology, 7(49): 3-19.

Ikegami, K. and Inoue, J., 1978: Mass balance studies on Kongma Glacier, Khumbu Himal. Seppyo (Journal of the Japanese Society of Snow and Ice), 40:12-16.

Karlén, W., 1973: Holocene glacier and climatic variations, Kebnekaise Mountains, Swedish Lapland. Geografiska Annaler, 55A: 29-63.

Kasser, P., 1967: Fluctuations of Glaciers 1959-1965. [Gentbrugge] Belgium: International Commission on Snow and Ice, International Association of Scientific Hydrology/UNESCO. $100 \mathrm{pp}$. individual responses, sometimes of opposing sign, are overwhelmed in favor of regional trend.

The value of these findings rests on the possibility that records of Trans-Himalayan glacier activity can extend our knowledge of the south Asian monsoon back in time. This population of glaciers is strategically located with respect to the macroscale interaction between land and ocean. Currently available data and the possibility of gaining pre- 1850 data on glacier fluctuations through field investigations may provide the climatic sequences needed for improved modeling of global climate.

Lamb, H. H., 1972: Climate: Present, Past and Future. Vol. I. London: Methuen. 596 pp.

Lamb, H. H. and Johnson, A. I., 1966: Secular Variations of the Atmospheric Circulation Since 1750. Geophysical Memoirs No. 10 (Fifth Number, Vol. XIV). London: Meteorological Office. 125 pp.

Mayewski, P. A. and Jeschke, P. A., 1979: Himalayan and Trans-Himalayan glacier fluctuations since AD 1812. Arctic and Alpine Research, 11: 267-287.

Mason, K., 1930: The glaciers of the Karakoram and neighborhood. Records of the Geological Survey of India, 63(2): 214-278.

Mercer, J. H., 1975: Glaciers of the Karakoram. In Field, W. O. (ed.), Mountain Glaciers of the Northern Hemisphere. Vol. I. U. S. Army Cold Region Research and Engineering Laboratory Publication, 371-409.

Parthasarathy, B. and Mooley, D. A., 1978: Some features of a long homogeneous series of Indian summer monsoon rainfall. Monthly Weather Review, 106: 771-781.

Paterson, W. S. B., 1969: The Physics of Glaciers. New York: Pergamon Press. 250 pp

Ramage, C. S., 1971: Monsoon Meteorology. New York: Academic Press. 296 pp.

Rao, Y. P., 1976: Southwest Monsoon. New Delhi: Indian Meteorological Department. 367 pp.

Weidick, A., 1972: Notes on Holocene events in Greenland. In Vasari, Y., Hyvärinan, H., and Hicks, S. (eds.), Climate Change in Arctic Areas During the Last Ten Thousand Years: A Symposium Held at Oulanka and Kevo, 4-10 October 1971. Acta Universitatis Ouluensis, Ser. A, Scientiae Rerum Naturalium, No. 3, Geologica, No. 1, 177-204.

Ms submitted February 1979 